\title{
Psicologia Jurídica: um Percurso nas Varas de Família do Tribunal de Justiça do Estado de São Paulo
}

A Journey In The Family Courts Of The State Of São Paulo

Psicología Jurídica:

Un Trayecto En Los Juzgados De Familia Del Tribunal De Justicia Del Estado De São Paulo

Evani Zambon

Marques da Silva

Pontifícia Universidade

Católica de São Paulo

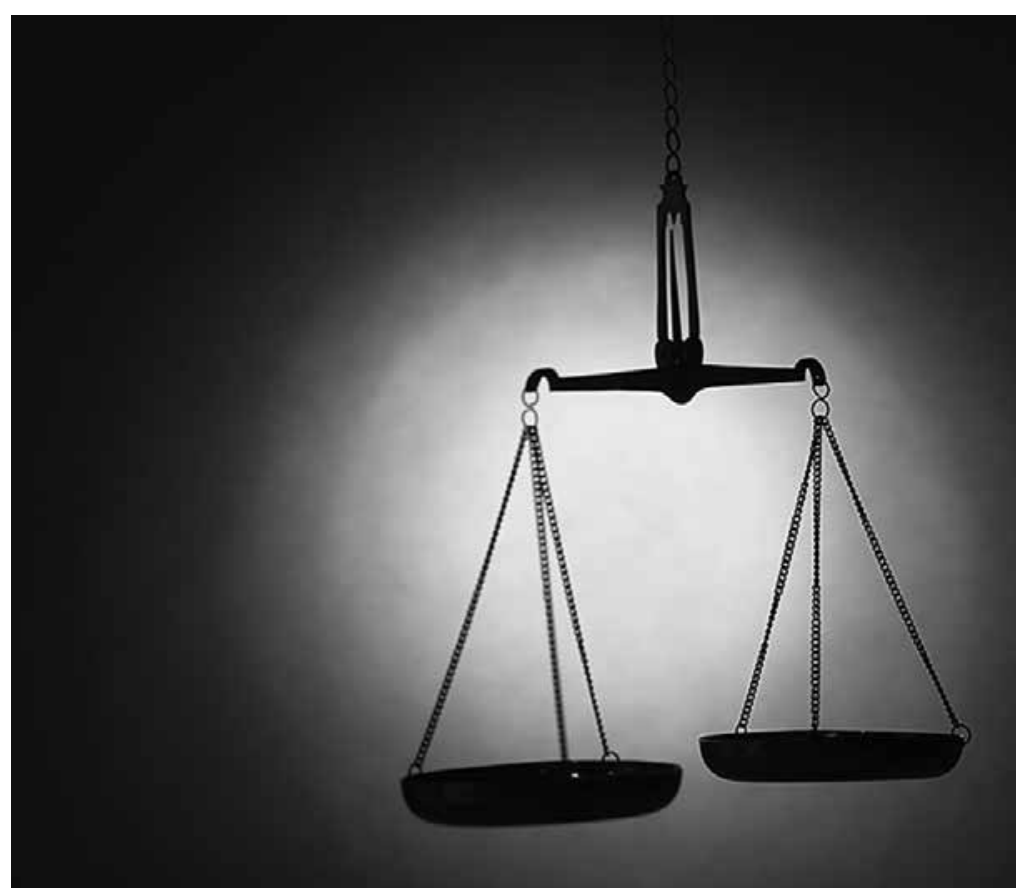


Resumo: A participação da Psicologia nos conflitos que chegam ao Poder Judiciário acompanhou o crescimento e o fortalecimento da profissão no Brasil. O percurso histórico e os assuntos atuais que demandam cada vez mais a contribuição do psicólogo serão, no presente artigo, apreciados sob as luzes da construção prática e teórica. As reflexões trazidas foram construídas com base no pioneirismo da equipe de psicólogos das Varas de Família do Tribunal de Justiça do Estado de São Paulo e nos estudos e pesquisas que a autora realiza em âmbito nacional e internacional. Questões como a formação acadêmica na área da Psicologia jurídica, a avaliação psicológica realizada e a comunicação dos resultados traduzidos nos laudos serão abordadas, além de mencionados também os documentos de referência da profissão (resoluções, referências técnicas) e os de âmbito legal (Estatuto da Criança e do Adolescente, Código de Processo Civil, recomendações do Conselho Nacional de Justiça e do Tribunal de Justiça de São Paulo). Esse cotidiano judicializado exige uma postura ativa e cuidadosa da Psicologia no enfrentamento da complexidade dos casos e no preparo para lidar com as demandas da própria sociedade, as quais atravessam diversas ciências conjuntamente, tais como o Direito e a Psicologia.

Palavras-chave: Psicologia. Psicologia forense. Avaliação psicológica. Perícia psicológica judicial.

Abstract: The contribution of psychology in the conflicts that come to the Judiciary followed the growth and the strengthening of the profession in Brazil. The historical and current issues that increasingly demand the contribution of the psychologist will, in this article, be examined under the light of theoretical and practical construction. The considerations brought were based on the pioneering team of psychologists, on the family courts of the Court of the State of São Paulo and on studies and research that the author performs nationally and internationally. Issues such as academic training in the area of forensic psychology, a psychological evaluation and reporting results translated in the reports will be discussed, and also mentioned the reference to documents of the profession (resolutions, technical references) and the legal framework (the Child and Youth Civil Procedure Code, recommendations of the National Council of Justice and the Court of São Paulo). This judiciary routine requires an active and careful way in dealing with the psychology of complex cases and in preparing to deal with the demands of society itself, which cut across various sciences together, such as law and psychology.

Keywords: Psychology. Forensic psychology. Psychological assessment. Judicial psychological expertise.

Resumen: La participación de la Psicología en los conflictos que llegan al Poder Judicial acompañó el crecimiento y el fortalecimiento de la profesión en Brasil. El trayecto histórico y los asuntos actuales que demandan cada vez más la contribución del psicólogo serán, en el presente artículo, apreciados bajo las luces de la construcción práctica y teórica. Las reflexiones traídas fueron construidas con base en el pionerismo del equipo de psicólogos de los Tribunales de Familia del Tribunal de Justicia del Estado de São Paulo y en los estudios e investigaciones que la autora realiza en el ámbito nacional e internacional. Cuestiones como la formación académica en el área de la Psicología jurídica, la evaluación psicológica realizada y la comunicación de los resultados traducidos en los laudos serán abordados, además de mencionados también los documentos de referencia de la profesión (resoluciones, informes técnicos) y los de ámbito legal (Estatuto del Niño y del Adolescente, Código de Proceso Civil, recomendaciones del Consejo Nacional de Justicia y del Tribunal de Justicia de São Paulo). Ese cotidiano judicializado exige una postura activa y cuidadosa de la Psicología en el enfrentamiento de la complejidad de los casos y en la preparación para manejar las demandas de la propia sociedad, las cuales atraviesan diversas ciencias conjuntamente, tales como el Derecho y la Psicología.

Palabras clave: Psicología. Psicología forense. Evaluación psicológica. Pericia psicológica judicial.

É com satisfação que escrevemos sobre uma área de atuação específica da Psicologia que nos absorve há mais de duas décadas, especialmente na ocasião em que o Conselho Federal de Psicologia abre espaço em sua respeitável revista Psicologia: Ciência e Profissão para expor percursos profissionais variados em sua edição histórica, que comemora meio século da regulamentação da profissão no Brasil.
Escrever sobre a nossa trajetória remete-nos a reflexões fundamentais e à expectativa de poder incentivar e disseminar o conhecimento a outros profissionais sobre a importância da Psicologia no âmbito das Varas de Família.

Na virada do século e já na segunda década do novo milênio, olhamos com respeito para a nossa história, para uma profissão felizmente com muitas lutas passadas para 
recordar-se. Na área da Psicologia jurídica, tivemos, em 1955, a publicação da obra de Emilio Mira y Lopes que já havia sido editada na Europa (1932) e que foi intitulada Manual de Psicologia Jurídica. A obra defendia o teor científico da Psicologia e a aplicabilidade de seus conhecimentos e instrumentos, e, além disso, valorizava uma Psicologia aplicada às instituições jurídicas.

Discorrer sobre o tipo de atuação possível de ser desenvolvida junto às famílias em conflito seria um terreno mais usual, debatido e extremamente organizado pelas várias correntes teóricas do conhecimento. Diferente disso, nosso propósito é apresentar a atuação do psicólogo nas Varas de Família, trazendo pontos históricos e também elementos atuais que já apontam demandas profissionais específicas e avançadas - em relação às famílias que judicializam seus conflitos, ou seja, que levam ao Poder Judiciário ou a um operador de Direito propriamente dito o pedido de auxílio e de soluções.

É sabido que o sistema de Justiça não consegue fazer frente a tudo que Ihe chega, seja na quantidade de casos, seja na complexidade dos assuntos. Nesse sentido, passa a realizar cada vez mais seus questionamentos aos profissionais de diferentes áreas, tais como o psicólogo, para que lhe apresentem contribuições que possam ir "além do que o cidadão comum pode intuitivamente compreender ou explicar" (Fonseca, Matos, \& Simões, 2008, p.3).

A participação da Psicologia na discussão dos inúmeros conflitos que chegam à Justiça foi impondo-se e mostrando suas possibilidades de contribuição para edificar um campo de saber diferenciado, que hoje recebe a denominação de Psicologia jurídica, judiciária ou forense (não nos dedicaremos aqui a traçar as nuances que definem cada tipo de nomenclatura, pois, para o nosso propósito, isso não se faz importante).
A enormidade de problemas atrelados às áreas da infância, juventude, família e idoso, da violência contra a criança e a mulher, do doente mental que delinque, da reabilitação do detento, da bioética e tantos outros, buscam o sistema de Justiça para a resolução ou o auxílio em suas dificuldades, e necessitam de uma compreensão não pautada apenas nas luzes da letra fria da lei. O prisma subjetivo edifica-se e impõese por detrás desses inúmeros processos que recebem uma capa, um número e que encerram o drama da vida de cada um. Indo além, podemos pensar também na riqueza que o Judiciário nos dá, nomeando as ações que ali adentram como processos.

(...) ninguém é dono de verdades absolutas a respeito do Homem, se é que seja este suscetível de verdades absolutas. De modo que tentar compreendê-lo em estado de sofrimento, como costuma apresentar-se aos profissionais de Direito, nos conflitos que lhe vem da inserção familiar, é tarefa árdua e, para usar de paradoxo, quase desumana, porque supõe não apenas delicadeza de espírito e disposição de ânimo, mas preparação intelectual e técnica tão vasta e apurada que já não entra no cabedal pretensioso dalgum jurista solitário. (Peluso, 1997, p. 7)

A história da Psicologia dentro dos Tribunais brasileiros já foi apresentada por muitos estudiosos, dos quais destacamos Rovinski (2009), Lago et al. (2009), Bernardi (2005) e Martins (1999), só para citarmos alguns. O nosso recorte será a Psicologia desenvolvida dentro do Tribunal de Justiça paulista, que foi edificando-se juntamente ao próprio desenvolvimento da profissão no País.

No início da década de 70 (séculoXX), játivemos notícias de juízes e de desembargadores que se valiam de avaliações psicológicas em algum momento do processo; eram profissionais que consideramos verdadeiramente à frente de seu tempo. Dentre eles, destacamos Antonio Luis Chaves Camargo, falecido em 2007, que começou a propor em 1980 a participação de 
"realizar perícias e emitir pareceres sobre a matéria de Psicologia". O primeiro Código de Ética da profissão, que surgiu em 1987, 18 anos após a criação dos Conselhos de Psicologia (Pereira, 1991) psicólogos voluntários nas audiências, criando assim, à época, as chamadas audiências interprofissionais (Camargo, 1982), que ocorriam nas então denominadas Varas de Menores, hoje Varas de Infância e Juventude.

As audiências interprofissionais representavam uma forma de atendimento dos casos, em juízo, através da prévia apuração da equipe técnica, composta por assistente social e psicólogo. Tais profissionais tinham como dever não só apresentar as medidas cabíveis dentro de suas respectivas áreas mas também confeccionar relatórios circunstanciados visando à decisão do processo (Camargo, 1982).

A profissão de psicólogo foi regulamentada no Brasil pela Lei no 4.112, de 27 de agosto de 1962, e, desde então, o Decreto no 53.464, de 1964, em seu artigo 4으, prevê que cabe ao psicólogo "realizar perícias e emitir pareceres sobre a matéria de Psicologia". O primeiro Código de Ética da profissão, que surgiu em 1987, 18 anos após a criação dos Conselhos de Psicologia (Pereira, 1991), mencionava um item específico para discorrer sobre as relações do psicólogo com a Justiça. Já o atual Código é datado de 2005, e também traz artigos elencando questões de sigilo, perícia e prestação de esclarecimentos em juízo, dentre outros, que balizam a atividade cotidiana.

Diversos outros documentos de respaldo profissional foram surgindo junto aos Conselhos Regionais e Conselho Federal de Psicologia, tais como resoluções, cadernos temáticos e manual de referência (os quais serão mencionados mais adiante). Tais documentos mostram a efervescência da área e a necessidade de normatizações específicas que visem, dentre outras coisas, à orientação ao psicólogo que atua com questões atinentes às Varas de Família.

A partir da entrada dos psicólogos no Tribunal de Justiça de São Paulo, na década de 80, e com o primeiro concurso público, em 1985, os profissionais foram ocupando espaços e galgando posições na instituição judiciária que se tornou referência para o restante do País. Foram criados 65 cargos efetivos e mais 16 cargos de chefia, o que constituiu um marco para o serviço público da época. Logo após a distribuição dos psicólogos aprovados para a atuação na área da infância e juventude, legitima-se o espaço para a atuação nas Varas de Família, sendo que o Fórum João Mendes, de São Paulo (capital), sediou a primeira equipe de profissionais especializados na área.

Por força da Lei Federal n 8069/90, que implantou o Estatuto da Criança e do Adolescente, as chamadas equipes técnicas ou interprofissionais (artigos $\mathrm{n}^{\text {os }} 150$ e 151) foram qualificando-se, integrando-se e não só sendo aceitas como tornando-se obrigatórias em todo o Brasil. Nesse sentido, citamos aqui a Recomendação no 2, do Conselho Nacional de Justiça, que faz alusão a esse fato e que será explicada mais adiante.

A prática no Tribunal paulista indica-nos que a proximidade dos juízes e outros operadores do Direito com os profissionais da Psicologia, ainda em sua maioria atuantes nas Varas de Infância e Juventude, foi paulatinamente disseminando o valor da ciência psicológica, e suas conclusões acabaram valorizadas em diversos territórios jurídicos. No interior paulista, é comum ainda os profissionais estarem lotados nas Varas de Infância e Juventude, mas prestarem serviços às Varas de Família ou Cíveis. Na capital, nos Fóruns regionais, poucos são os setores técnicos que estão individualizados e que prestam serviços diferenciados entre os assuntos das Varas de Infância e Juventude e os das Varas da Família. Normalmente, segundo estudos desenvolvidos pela Associação dos Assistentes Sociais e Psicólogos do Tribunal de Justiça de São Paulo (AASPTJ-SP), os profissionais acumulam as duas áreas. 
A união e os esforços dos psicólogos que atuam nos Tribunais de todo o País foram reconhecidos. Os profissionais se organizaram como categoria e criaram associações regionais, das quais destacamos a Associação dos Assistentes Sociais e Psicólogos do Tribunal de Justiça de São Paulo (AASPTJ$\mathrm{SP})$, que possui a finalidade de defender os interesses gerais e as reivindicações desses profissionais e de promover o aprimoramento técnico-profissional e cultural de seus associados. A referida associação paulista foi criada em 1992, e conta atualmente com sede própria e com aproximadamente 1.230 associados entre psicólogos e assistentes sociais atuantes e aposentados dos quadros técnicos do Tribunal de Justiça de São Paulo.

$\mathrm{Na}$ área acadêmica, os psicólogos jurídicos também demarcam firmemente sua presença participando de encontros, congressos e simpósios nacionais e internacionais. Destacamos eventos que desde 1987 são realizados em São Paulo (I Encontro de Assistentes Sociais e Psicólogos do Poder Judiciário) e em diversos Estados brasileiros, tais como Minas Gerais, Bahia, Rio Grande do Sul, Santa Catarina e Rio de Janeiro, só para citarmos alguns. No âmbito internacional, foi realizado, em 2012, o VII Congresso Iberoamericano de Psicologia Jurídica, no Equador, evidenciando ampla participação do psicólogo nas questões da Justiça, seja no volume de trabalhos e conferências apresentadas, seja na projeção e na apresentação de discussões e propostas cada vez mais atinentes a um contexto de crescente complexidade.

Apesar de a disciplina Psicologia Jurídica (ou forense ou judiciária) já fazer parte de algumas grades curriculares de cursos superiores de Psicologia em todo o País, ela ainda não integra obrigatoriamente o currículo dos futuros psicólogos. Muitas instituições oferecem disciplinas que tangenciam o assunto da Psicologia jurídica, mas que ainda deixam um grande espaço para que os alunos conheçam e ampliem sua formação, inclusive sobre cidadania, ética e assuntos específicos que atravessam a subjetividade dos indivíduos no mundo atual.

$\mathrm{Na}$ experiência dos profissionais pioneiros do Judiciário paulista, dentre os quais nos incluímos, a formação curricular nada trazia sobre a possibilidade de a Psicologia ser aplicada aos tribunais. Assim, apesar de matérias que falavam de instituições, psicodiagnóstico, técnicas de avaliações psicométricas diversas, teorias de abordagem e conhecimento das pessoas e de seus problemas, desenvolvimento infantil e adolescente, ética e estatística, só para citarmos algumas, nada havia especificamente para nortear o profissional que fosse atuar em tribunais. Perguntas eram formuladas: Como responder à demanda? Como organizar uma avaliação com fins periciais? Como lidar com o sigilo? Como discutir o caso com um operador do Direito? Quais os limites da atuação que deveriam ser fornecidos? Como redigir e comunicar o trabalho? Quem é o nosso cliente? E assim por diante.

Ainda hoje padecemos com essas dificuldades, ou seja, profissionais que vão a campo sem o conhecimento das ferramentas adequadas ou propícias para a atuação junto aos operadores do Direito. Tal postura causa uma exposição negativa do psicólogo, já que, na atualidade, diga-se de passagem, ninguém está livre de, ainda que não tenha optado por trabalhar no sistema da Justiça, ter seu trabalho solicitado para ilustrar um processo judicial qualquer, para participar de uma audiência e outras entradas comuns. Para nós, a Psicologia jurídica está espalhada em qualquer âmbito, sendo seu conhecimento imperioso para aqueles profissionais da clínica, da escola, dos hospitais, das empresas.

Em complementação ao nosso entendimento sobre isso, Maciel e Cruz, ao escreverem sobre 
(...) Exige-se,

além disso, que a informação fornecida pelos peritos esteja ancorada numa sólida metodologia científica"

(Fonseca, Matos, \& Simões, 2008,

p.6). a avaliação psicológica em processos judiciais, colocam que:

O trabalho do psicólogo no campo jurídico, ainda que tenha se ampliado, não somente no campo pericial, ainda carece de discussão e desenvolvimento curricular que the faça referência. Essa deficiência reflete-se, também, nos casos em que são necessárias intervenções dos Conselhos de Psicologia, principalmente dos Comitês de Ética, quando tratam sobre laudos e conteúdos afins, onde é possível observar a escassez de profissionais que trabalham com essa demanda e que apresentem competência técnica específica para compreender a natureza, limites e possibilidades do trabalho pericial. (2009, p. 46)

Para estudiosos europeus, por exemplo, é sabido que "não basta uma simples transferência directa dos conhecimentos (ou resultados científicos) da Psicologia ou da psiquiatria para o domínio da Justiça (...) Exige-se, além disso, que a informação fornecida pelos peritos esteja ancorada numa sólida metodologia científica" (Fonseca, Matos, \& Simões, 2008, p. 6).

Na tentativa de dar suprimento à formação profissional ou de levar conhecimentos atuais para aqueles que assim o desejam, diversos cursos estão sendo oferecidos em todo o País. Em São Paulo, destacamos o proposto pelo Instituto Sedes Sapientiae, que, embora não seja credenciado pela ABEP (Associação de Ensino em Psicologia) como especialização, possui, em seu quadro de docentes, psicólogos pioneiros nas diferentes áreas de atuação da Psicologia jurídica.

Na área de pós-graduação strictu sensu, também inúmeros trabalhos estão sendo apresentados ao longo das últimas décadas, em uma tentativa de sistematizar o conhecimento, que, ao menos em se tratando do Estado de São Paulo, teve seu início de forma prática e pouco embasada teoricamente, já que não havia um corpo de conhecimentos sistematizado na área. Nossos atuais Mestres e Doutores são profissionais que, se não atuam diretamente na área, debruçam-se a pesquisar a Psicologia jurídica em profundidade, redigindo dissertações e teses de alto nível e com grande legitimação pela comunidade acadêmica.

Paralelamente a esse avanço, em 2004, tivemos a criação do Conselho Nacional de Justiça (CNJ). O órgão, instalado em 2005, foi criado em obediência ao determinado na Constituição Federal, nos termos do art. 103-B, e é voltado para a reformulação de quadros e meios no Judiciário, sobretudo no que diz respeito ao controle e à transparência administrativa e processual. Suas ações são voltadas para o planejamento, a coordenação, o controle administrativo e o aperfeiçoamento do serviço público na prestação da Justiça.

O Conselho Nacional de Justiça vem editando resoluções que paulatinamente colaboram para o ajustamento dos psicólogos nas áreas da Justiça. Assim, podemos destacar a Resolução no 75, que propõe, dentre outras matérias, a Psicologia Judiciária, como parte da formação importante e necessária para o ingresso às carreiras da magistratura.

A Resolução no 75 menciona o que especificamente deve ser ensinado ao futuro magistrado (estadual, federal, do trabalho e militar) sobre a matéria Psicologia jurídica. O texto se subdivide em quatro itens previamente indicados pelo Conselho Nacional de Justiça, os quais tivemos a oportunidade de desenvolver em obra própria (Silva \& Castro, 2011).

Antes disso, a Resolução no 2, editada em 2006, já recomendava aos Tribunais de Justiça dos Estados que, em observância à legislação de regência, adotassem as providências necessárias à implantação de equipes interprofissionais, próprias ou mediante convênios com instituições universitárias. 
O objetivo da citada resolução é que os tribunais, por meio de suas equipes, possam dar atendimento às Comarcas dos Estados nas causas relacionadas a família, crianças e adolescentes, devendo, no prazo de seis meses, informar a esse Conselho Nacional de Justiça as providências adotadas.

Uma rápida consulta a essas resoluções pode mostrar-nos a disposição do órgão federal em inserir o profissional psicólogo de forma cada vez mais organizada tecnicamente nos quadros dos Tribunais de Justiça brasileiros, valorizando não só a contribuição histórica com laudos, pareceres e relatórios mas também com a formação mais ampla do operador de Direito.

Outro destaque importante, embora mais genérico, sobre a atuação do psicólogo é a Resolução no 125, editada em 2010, que dispõe sobre a Política Nacional de Tratamento Adequado dos Conflitos de Interesse no âmbito do Poder Judiciário. Tal medida representa um avanço, uma vez que os tribunais brasileiros deverão organizar-se para oferecer, por exemplo, a conhecida mediação, que vem a ser, dentre outras, uma técnica alternativa (à adversarial) de resolução de conflitos.

A legislação interna do Tribunal de Justiça paulista desde 1985 possui normatização própria para a organização dos Setores Técnicos (Normas de Serviço da Corregedoria Geral - Cap. XI). O Provimento n.ㅇ 236/85, do Conselho Superior da Magistratura do Egrégio Tribunal de Justiça de São Paulo, já dispunha sobre a organização dos setores técnicos (Serviço Social e Psicologia), e, mais adiante, surge o Provimento no 6/91, da Corregedoria Geral da Justiça, propondo um grau maior de organização das equipes.

Em 2005, visando a organizar e a atender as demandas internas, o Tribunal de Justiça de São Paulo cria o Núcleo de Apoio Profissional ao Assistente Social e Psicólogo do Tribunal de Justiça de São Paulo. Esse núcleo foi criado tendo em vista a necessidade de assessoramento técnico aos profissionais e a padronização das rotinas existentes, a normatização e a centralização de diretrizes de trabalho de ordem técnica e administrativa e a orientação e o acompanhamento de profissionais (de Serviço Social e Psicologia) no exercício de suas funções interdisciplinares:

As atribuições dos assistentes sociais e psicólogos do Tribunal de Justiça de São Paulo foram construídas por meio de intensas discussões dos profissionais do Judiciário. Essas atribuições foram normatizadas pela Secretaria de Recursos Humanos (antigo Departamento Técnico de Recursos Humanos), e, após aprovação da Presidência do Tribunal de Justiça de São Paulo, publicadas. O Comunicado $\mathrm{n}^{\mathrm{o}}$ 308/2004 (D.O.J. de 12/03/2003) versa sobre as atribuições dos assistentes sociais e o de no 345/2004 (D.O.J. de 26/05/2004) sobre as atribuições dos psicólogos. (TJSP, 2008)

Assim, por nos sentirmos parte dessa história que com tanto carinho, fôlego e profissionalismo tentamos construir é que chamamos a atenção dos psicólogos interessados no assunto. É necessária a ocupação responsável desse crescente campo de atuação, mas que, como qualquer outro, é exigente e, por vezes, disciplinador.

\section{A atuação nas Varas de Família - o caminho construído}

O psicólogo iniciou sua atuação nas Varas de Família como perito. Foi sendo chamado, como já dito inicialmente, na década de 70 (século XX), a emitir parecer sobre matéria que envolvia disputas de guarda e regulamentações de visitas de filhos.

O respaldo legal de um perito judicial, seja ele de qualquer área, está definido pelo Código de Processo Civil (Lei no 5.869/73), alterado parcialmente em 1992 (Lei no 8.455). Os artigos que fazem referência ao trabalho do 
Rovinski (2004)

explicita que não

há nenhuma

necessidade

de formação

específica na

área forense,

ainda que

esta possa

trazer maior

credibilidade

ao relatório do

expert. perito são o no 139 (que menciona o perito como um auxiliar da Justiça) e os $n^{\text {os }} 145$ a 147 e 420 a 439 (que dispõem sobre as funções do perito e a prova pericial).

A perícia é um meio probatório (Rosa, 1999; Amaral Santos, 1994), sendo que, nela, o profissional verifica e analisa fatos interessantes à causa, transmitindo ao juiz seu respectivo parecer. Existem outros meios de provas, tais como a testemunhal e a documental, porém a prova pericial difere das demais por ser realizada por um especialista na matéria.

A perícia é uma atividade técnica e processual, que se materializa no processo através do laudo ou de qualquer outra forma legalmente prevista. Os elementos para a perícia são, basicamente, a nomeação do perito, a indicação de assistentes técnicos pelas partes, a apresentação de quesitos, e, posteriormente, as considerações críticas das partes, e outros esclarecimentos do perito e dos assistentes dentro ou fora da audiência.

Em tese, todos os profissionais psicólogos são considerados peritos, já que qualquer profissional que se encontre registrado junto ao seu órgão de classe e que possua qualificação técnica para responder as questões formuladas em juízo está qualificado como expert, ou seja, é considerado perito em matéria de Psicologia. Rovinski (2004) explicita que não há nenhuma necessidade de formação específica na área forense, ainda que esta possa trazer maior credibilidade ao relatório do expert.

A perícia é materializada por técnicas conhecidas de avaliação psicológica, e requer conhecimentos específicos em processos básicos de investigação: compreensão da demanda instalada e sua relação com o domínio jurídico a ela direcionada, definição das estratégias e instrumentos de exame psicológico mais adequados à demanda instalada, verificação da pertinência dos quesitos apresentados em juízo ao perito e elaboração de comunicação psicológica por meio de laudo (Maciel \& Cruz, 2009, p.46).

O trabalho estritamente pericial sempre foi solitário. No máximo, conseguíamos atuar de forma multidisciplinar, ou seja, levando nosso ponto de vista ao assistente social ou ao juiz, sem maiores construções. Sobre isso, no trabalho de Shine e Strong (1998), fica demarcado que Psicologia e Direito são campos distintos, com atuações diferentes, e que o Direito não é interdisciplinar, mas multidisciplinar, não cabendo, ao menos na organização atual, falar-se em participação na sentença, na intervenção e na decisão judicial, por exemplo.

Hoje conseguimos enxergar e experimentar avanços no âmbito da Psicologia jurídica, pois cada vez mais os operadores do Direito se valem de elementos da subjetividade para fundamentar suas sentenças e buscam o profissional para discussões antes de redigir seu trabalho.

Como exemplo recente, podemos citar a decisão do Superior Tribunal de Justiça, em voto proferido pela Ministra Fátima Nancy Andrighi, que reconheceu o abandono afetivo de um pai em relação à filha, estipulando um valor para o ressarcimento do aludido dano emocional. Além disso, na mesma esteira, ainda tratou da alienação parental, de dano familiar e de dever de cuidar (Recurso Especial $\mathrm{n}$ o 1.159.242, Terceira Turma do STJ, julgado em 24/04/2012 - www.stj.jus.br ).

Apesar de não ser este o local de discussão do assunto com seus liames psicológicos, limitamonos apenas a apontar que a construção do raciocínio do mencionado tribunal superior foi pautada em conhecimentos da área da Psicologia (em parte) para entender e proferir a decisão, que certamente possuirá um eco emocional na vida dos envolvidos. 
Sobre isso, já observou Nalini quando destaca a importância de o magistrado não ser apenas um "compilador de jurisprudência, limitando-se a aplicar a orientação dominante à hipótese submetida ao seu julgamento, já que esse tipo de serviço poderia ser prestado por um computador" (1977, p.6). Esclarece o autor, na obra citada, que o juiz não deve limitar-se a ser um burocrata repetidor de decisões alheias, sugerindo que ele prolate suas sentenças com sentimento, fazendo um paralelo entre os radicais dos vocábulos sentença e sentimento.

Em outra oportunidade, já escrevemos (Silva, 2005) que a visão interdisciplinar que a Psicologia jurídica vem buscando junto aos tribunais é o verdadeiro resgate da dignidade da pessoa humana, como ser que pensa, vive e é dotado de subjetividade. Transformar os sujeitos não apenas em sujeitos de direitos mas em indivíduos dignos e em plenas condições de exercer sua cidadania tem sido o lema dessa grande área, que, pela sua importância, foi alçada a uma especialidade pelo Conselho Federal de Psicologia em 2001 (Resolução CFP no 002/2001).

A demanda inicialmente pericial para os psicólogos das Varas de Família foi alternandose com pedidos de acompanhamento de casos e de intervenções que paulatinamente delineiam modalidade de atuação mais aberta e mais interventiva. Pode-se dizer que houve boa aceitação por parte dos juízes sobre isso, uma vez que grande parte deles, na verdade, desconhecia as diversas possibilidades de atuação do psicólogo. Para a Justiça, o trabalho é importante e válido quando consegue auxiliar os juízes a dirimirem suas dúvidas e entenderem melhor os aspectos psicológicos do caso.

A própria complexidade da sociedade, o avanço das comunicações e a rapidez com que se buscam soluções foram atingindo quase que em sua totalidade o fazer profissional dos psicólogos voltados para as questões familiares. Hoje as questões que buscam as soluções no Judiciário envolvem tamanha complexidade que os recursos de avaliação até então conhecidos passam a não mais conseguir auxiliar ou oferecer respostas.

Assim, definirmos possibilidades de risco que envolvem filhos, atividades emocionais desestruturantes de genitores, tais como o que hoje se discute como alienação parental, sofrimento de bullying, assédios de várias naturezas, nexos causais gerados por abandonos afetivos e tantas outras situações que chegam ao psicólogo necessitam de uma implementação específica dos estudos e pesquisas para que possamos situar-nos e entendermos que proteção nos cabe fornecer ao ser humano acerca de sua saúde mental, ou ainda, como podemos colaborar com o sistema de Justiça e com o ser humano de forma integral, quando nos solicitam institucionalmente nossas opiniões.

Interpretar e avaliar não significa julgar. Comprometer-se com um diagnóstico ou com um prognóstico - quando possível - não significa impingir ao outro sofrimento, mas sim, possibilidade de libertação por meios necessários da aplicação de uma justiça que ele (usuário da Justiça) próprio procurou, de uma lei que ele próprio buscou e de um atendimento e de uma escuta que ele clama, como cliente de um Judiciário que é público, ou seja, que está para servir o povo, e não para servir-se desse mesmo povo.

Sobre isso, gostaríamos de indicar que, segundo o documento redigido pelo Setor de Psicologia das Varas de Família do Fórum Central de São Paulo, por ocasião da consulta pública do Centro de Referências Técnicas em Psicologia e Políticas Públicas (CREPOP), em 2010, e apresentado em evento do CRPSP, no mesmo ano, entendemos que não há uma descontinuidade entre o ato de avaliar e o de julgar. Julgar reduz-se, na realidade, 
a resolver de certa maneira, depois de se ter analisado uma situação. O perito, tenha ou não consciência disso, não é neutro em sua avaliação, que tem por objetivo servir como uma das bases de julgamento para o juiz. É óbvio que o juiz é quem julgará do ponto de vista jurídico. O perito emitirá um parecer sobre qual genitor the parece mais indicado, se é que há algum, do ponto de vista psicológico, para permanecer, usando o exemplo acima proposto, com a guarda: compartilhada ou unilateral, ou com outro membro da família. O que se pede de um perito é que, dentro de sua área de conhecimento, dentro dos referenciais científicos atuais, diga sobre a matéria que está sendo discutida no processo. Não adianta apenas descrever a personalidade de cada um dos envolvidos. É necessário emitir um parecer sobre essa questão, em certos casos, até demonstrar que não há uma alternativa melhor que outra (CRP SP, 2010, p.8).

Assim, a prática atual nas Varas de Família vem revelando cada vez mais a necessidade de o psicólogo possuir um raciocínio pluridimensional, sem deixar, porém, de avaliar e de diagnosticar, revendo constantemente a inserção socio-histórica dessa avaliação e, dentre outras coisas, a visão de homem que está por detrás do escrutínio.

De uma vez por todas, a avaliação psicológica precisa ser compreendida como competência imprescindível ao psicólogo como é disposto nas diretrizes curriculares que regem a formação profissional - e como área que requer formação específica e atualizada (...) Avaliar é necessário em diversos contextos de atuação, pois, além de fornecer informações preciosas dos aspectos psicológicos dos processos avaliados, contribui para uma atuação mais refinada e precisa (...) (Noronha \& Reppold, 2010, p. 200)

Seria interessante se a perícia conseguisse desenvolver ou estimular o surgimento de uma autonomia interna na clientela das Varas de Família, já que, em alguns casos, o momento pericial, quando outro trabalho não teve ou não pôde ter lugar (como, por exemplo, a psicoterapia, a mediação), é o primeiro e único de que a família dispõe para entrar minimamente em contato com seu mundo interno. No entanto, sabemos que as estruturas de personalidade e fatores cruciais concretos muitas vezes impossibilitam esse esperado crescimento.

Embora não seja o caso de fugirmos ao papel pericial, aquele que nos enquadra na tarefa de Vara de Família, a nossa postura e, sem dúvida alguma, a documentação escrita realizada pelo psicólogo, aqui chamada de laudo, são ferramentas de grande valia para um estímulo e incentivo aos indivíduos. Este último é um instrumento limitado, sabemos, já que pode ser usado como alimento/ fermento do litígio, mas é o que temos como próprio para a tradução do nosso trabalho, que nem sempre pode ser findado com entrevistas devolutivas, tal como no modelo clínico.

Nesse sentido, devido à nossa atuação profissional, desenvolver-se especificamente junto às Varas de Família, a demanda de casos recebidos é, na maioria das vezes, para a realização de perícias. Por intermédio desse tipo de trabalho, busca-se a definição, como já explicitado em outro trabalho, "quem do ponto de vista emocional possui maiores ou melhores condições, naquele momento, de assumir o filhos, em caso de disputas de guarda, por exemplo" (Silva, 1999).

Esse fato vem trazendo-nos inquietações e forçosamente remetendo-nos a um questionamento sobre as possibilidades efetivas que o psicólogo possui para ler a situação emocional delineada, e, para além disso, também intervir. De algum modo, é importante darmos sentido para que a coleta de dados, as entrevistas e as observações 
possam fazer algum tipo de eco dentro de um contexto vivencial mais amplo e profundo de sua história.

A alternativa proposta por Martins é no sentido de utilizarmos as avaliações psicológicas dentro do âmbito jurídico de forma a não apenas compreendermos as dificuldades internas das pessoas mas também seus recursos individuais, familiares e relacionais, que podem ser utilizados na solução das questões. Nossas sugestões inseridas nos laudos são aceitas em 94,23\% dos casos, segundo uma pesquisa sobre a influência dos laudos psicológicos nas decisões judiciais nas Varas da Família do Tribunal de Justiça de São Paulo (Rodrigues, Couto, \& Hungria, 2005, p.31). Isso, é obvio, agrega não só maior responsabilidade ao trabalho mas também a possibilidade de torná-lo um instrumento de transformação.

Concordamos com Reis quando afirma que os psicólogos que atuam nesse meio "muitas vezes caminham no sentido de reproduzir os conflitos familiares, em vez de inventar novos meios de desfazê-los ou transformálos" (2009, p.19), mas também apontamos que, apesar de considerarmos que as Varas de Família sejam o local onde se exercitam poderes, traduzidos muito bem pela citada autora como uma verdadeira guerra dos sexos, há de se destrinchar tecnicamente, e valendo-se de pressupostos científicos, quais são os casos em que realmente isso está prevalecendo e quais exibem clara ou subliminarmente situações de risco para o(s) filho(s) envolvido(s).

Qualquer avaliação que envolva crianças pode ser vista hoje sob o princípio da dignidade humana, ou seja, de levar o direito de ser digno a um ser merecedor de respeito (Marques da Silva \& Miranda, 2009).

Trabalhos realizados fora do âmbito judicial devem ser implementados, e são, na maior parte das vezes, a melhor alternativa ao trabalho pericial. Não há como desvalorizarmos a utilização de ferramentas que ajudem aqueles que estão em conflito a encontrarem, por si sós, o "leme do próprio barco interior" (Silva, 1999) sem precisarem recorrer a um terceiro, no caso o Judiciário, para a resolução de suas dificuldades ou amarguras.

Como já tivemos a oportunidade de escrever em trabalho de doutorado (Silva, 2005) sobre a Psicologia jurídica, sempre devemos partir do pensamento que as pessoas são capazes de decidir sobre a própria vida; além disso, observando-se os povos através da história da civilização, podemos notar que eles buscam maneiras diversas de resolver suas desavenças, atendo-se ao momento político e históricosocial vigente. Dessa maneira, surgem como uma forte tendência do momento atual as discussões que priorizam formas alternativas de resolução dos conflitos, ou seja, formas alternativas à via judicial clássica, que é a adversarial.

Além disso, o século XXI aponta-nos com clareza a ineficiência da Justiça no que se refere à administração do tempo, um problema crônico do sistema judiciário brasileiro e que acarreta graves consequências sociais. O aumento da população e da litigiosidade descortina uma realidade em que o Estado é incapaz de resolver todos os conflitos e necessita adotar caminhos com novos parâmetros atrelados a uma mentalidade de composição, de autorregulação.

Métodos conhecidos como mediação, conciliação e negociação vêm sendo adotados paulatinamente pelos tribunais brasileiros nos mais diferentes tipos de processos, construindo uma verdadeira cultura que se contrapõe à cultura litigante, que é a denominada cultura da paz. 
A profusão de ideias e pessoas ocorre numa velocidade tal que reclama por estruturas flexíveis, renovadas e adaptáveis, através de procedimentos simples, céleres e eficazes e que tenham condições de se contrapor ao peso do formalismo da Justiça tradicional, materializada em um tribunal e no complexo tecnicismo processual que caracteriza o seu funcionamento. (Silva \& Castro, 2011, p. 64)

Na ponta profissional em que atuamos, os casos infelizmente já chegam bastante comprometidos do ponto de vista emocional, muitas vezes com distorções significativas na apreciação do mundo familiar e global a sua volta. As situações invariavelmente envolvem filhos com necessidades básicas negadas, distorcidas, ou pior, destruídas de forma perigosa não só para a sua integridade psíquica como também para a física.

Parte das situações que chegam para as perícias psicológicas não possuem qualquer possibilidade de serem mediadas. Há neles psicopatologias, queixas de abusos (físicos, sexuais e psicológicos) por vezes declaradas, por vezes escamoteadas, além de graves distorções nos dinamismos psíquicos que, em última instância, necessitam de um instrumento legal para salvaguardar o(s) filho(s) de inúmeras possibilidades de risco. Segundo Vezzulla,

(...) É fundamental que o mediador tenha bem presente, para poder transmitir aos mediados, que a mediação apenas os poderá ajudar se eles desejarem preservar o relacionamento, melhorá-lo ou pelo menos não o prejudicar. Se esse interesse não existir, a mediação perde a maior de suas forças e os acordos correm o risco de não serem cumpridos, pela falta de desejo de reconstruir ou preservar o relacionamento anterior à contenda, ou de recriar um novo relacionamento, já que o antigo fracassou. (2001, p. 34)

Além disso, o contingente de profissionais psicólogos concursados, que atuam no tribunal paulista junto às Varas de Família, possui o impedimento legal de realizar trabalhos de conciliação, já que o psicólogo é remunerado nessa instituição. A título de ilustração, mencionamos o provimento no 953/2005, do Conselho Superior de Magistratura:

Artigo $3^{\circ}$ - Poderão atuar como conciliadores, voluntários e não remunerados, magistrados, membros do Ministério Público e Procuradores do Estado, todos aposentados, advogados, estagiários, psicólogos, assistentes sociais, outros profissionais selecionados, todos com experiência, reputação ilibada e vocação para a conciliação, previamente aferida pela Comissão de Juízes ou Juiz coordenador, quando não constituída a Comissão.

\section{$\S 1^{\circ}$ - Os conciliadores não terão vínculo empregatício e sua atuação não acarretará despesas para o Tribunal de Justiça (grifo nosso).}

Nos casos que envolvem disputa de guarda, por exemplo, é evidente que a criança necessita de ambos os genitores; pai e mãe têm importante parcela na formação do filho, mas, por exemplo, diante do recrudescimento da criança, ou seja, de sua negativa veemente de não mais residir com a genitora, temos necessariamente que avaliar dados de sua personalidade e dinamismos psíquicos relativos aos seus padrões cognitivos e afetivoemocionais, que, no cruzamento com as necessidades do filho, podem estar sendo mal assimilados na relação. Necessitamos avaliar as possibilidades (ou distúrbios emocionais) na família, nos indivíduos ou nos vínculos que possam estar sobrecarregando e indicando que talvez essa criança sofra prejuízos em seu desenvolvimento emocional.

Para um psicólogo jurídico, atuante no tribunal, é importante apreender o leque de possibilidades e de internalizações que a criança e o adolescente fazem acerca de suas figuras parentais; para tal, as técnicas de avaliação muito contribuem para o 
refinamento do olhar psicodiagnóstico. No entanto, saibamos olhá-las com humildade, uma vez que, como nos disseram Simões e Lopes, "a avaliação é uma tarefa difícil e, ao mesmo tempo, redutora e imprecisa quando se trata de resumir toda a complexidade das condutas humanas" (2004, p.195).

No entanto, o olhar investigativo, que vai além da curiosidade científica e vai também examinar e ponderar sobre a realidade factual em si, é muito importante também, já que dará indicativos acerca de quem são aquelas figuras parentais na realidade e se podem apresentar ou não algum tipo de ameaça ou risco ao crescimento físico-emocional da criança (Castro, 2003).

Identificamo-nos muito com o trabalho desenvolvido por Castro sobre disputa de guarda de filhos, pois a autora assume, com maestria científica, a necessidade de também se avaliar como são os pais na realidade, demarcando uma das diferenças entre o psicodiagnóstico clínico daquele realizado por ocasião da perícia psicológica.

(...) Em psicodiagnóstico clínico, muitas vezes ouvimos a máxima de que o que importa não é a realidade objetiva. O que importa é como a criança vivenciou uma determinada situação, tenha ela acontecido ou não. No Judiciário, importa não só como foram introjetadas as figuras parentais mas também como os pais são na realidade. Se há alegação de abuso sexual, é necessário que haja uma investigação minuciosa para concluir se, de fato, ocorreu. (Castro, 2003, p. 37)

Salientamos, dessa forma, a necessidade constante de atualização do profissional que atua nos Tribunais, não apenas em relação às descobertas da ciência psicológica mas também no tocante aos códigos legais já estabelecidos e aos avanços constantes empreendidos pelas sociedades, sempre inscritas em momentos históricos e culturais que as remetem a um contínuo movimento.
Os processos que envolvem avaliações de responsabilidades parentais são reconhecidos na literatura como os mais complexos, com situações de litígio intenso e reiterado, e, não raro, com o desajustamento das crianças envolvidas. Muitos autores sugerem inclusive que se trata de uma das áreas mais difíceis da avaliação psicológica forense, chegando a considerá-la um contexto de risco para os profissionais, aquela onde é mais provável virem a confrontar-se com queixas e processos que questionam e impugnam as suas práticas (Pereira \& Matos, 2011, p.315).

Já há algum tempo, diversos países estrangeiros, atentos ao surgimento de queixas nos Comitês de Ética sobre as perícias nas áreas que estudam as regulações das responsabilidades parentais e também alertados pela inconsistência e pela arbitrariedade metodológica desses trabalhos, começam a publicar pequenos guias para o direcionamento dessa atuação. Segundo Pereira e Matos (2011, p.315), a Associação Americana de Psicologia (APA) publica as primeiras orientações para a prática pericial forense em 1994, seguindo-se depois muitas outras. São os chamados guidelines, que também trazem suas vicissitudes e devem ser vistos com cautela e criticidade em função de, entre outras coisas, não haver uma padronização para as diversas culturas que os utilizarão.

Além das sugestões da referida associação, outras orientações internacionais foram surgindo, como é o caso das boas práticas publicadas online pela AFCC - Association of Family and Conciliation Courts, que é uma associação internacional e interdisciplinar de profissionais dedicados à resolução de conflitos familiares (Pereira \& Matos, 2011, p.318).

No Brasil, foi oferecido à categoria pelo Conselho Federal de Psicologia o documento de referências para atuação do psicólogo em 
Vara de Família (CFP, 2010), o qual se pautou em metodologia do Centro de Referência Técnica em Psicologia e Políticas Públicas (CREPOP). As referências são, no entender no órgão federal, baseadas nos princípios éticos e políticos norteadores do trabalho dos psicólogos, e possibilitam a elaboração de parâmetros compartilhados e legitimados pela participação crítica e reflexiva da categoria.

Sobre o conteúdo do documento, a equipe paulista, pioneira na atuação com casos das Varas de Família e, diga-se de passagem, a mais antiga que milita na área, manifestouse em documento próprio cuja relevância motivou um evento no Conselho Regional de Psicologia - 6 ${ }^{\text {a }}$ Região. As considerações tecidas integram documento próprio, não publicado, porém protocolado (no CRP $-6^{\underline{a}}$ Região) em função da consulta pública que foi realizada.

O Conselho Regional de Psicologia de São Paulo, considerando o número crescente de representações relativas ao trabalho do Psicólogo no contexto do Poder Judiciário, especificamente nas questões de família, realizou dois encontros (2005 e 2006) a fim de debater a relação dos peritos com os assistentes técnicos e de construir subsídios para um melhor exercício profissional. Disso decorreu a necessidade da criação de um grupo de trabalho (GT) com representantes do Conselho Regional de Psicologia de São Paulo (CRP SP), profissionais e entidades representativas na área. Das discussões do mencionado grupo, derivou uma recomendação ao Tribunal de Justiça de São Paulo, que o aprovou na forma do Comunicado no 01/2.008, do Núcleo de Apoio Profissional de Serviço Social e Psicologia do Tribunal de Justiça de São Paulo, publicado no Diário Oficial da Justiça em 14 de outubro de 2008 (CRP SP, 2010).

Após a publicação, em novembro de 2008, o Conselho Regional de São Paulo realiza outro evento, chamado agora A Ética Própria da Psicologia - Mudanças na Relação Assistente Técnico e Perito, visando à promoção de um amplo debate sobre o assunto. Todo o percurso paulista foi traduzido em uma publicação na série Cadernos Temáticos, que objetiva registrar e divulgar os debates realizados no Conselho em diversos campos de atuação da Psicologia (CRP SP, 2010).

Acompanhando a discussão nacional, em junho de 2010, o Conselho Federal de Psicologia edita a Resolução no 8, que, em suma, dispõe sobre a relação perito e assistente técnico no Poder Judiciário. A sobreposição das atuações profissionais evidenciou necessitar de uma regulação, muito bem realizada por esse instrumento.

Em síntese, não basta uma simples transferência direta dos resultados e dos conhecimentos científicos da Psicologia para as questões que envolvem perícias nas Varas de Família. Em conformidade com a nossa prática e em face da literatura consultada, é importante traçar metodologias específicas e tratar o assunto com rigor e seriedade. Vimos que, pela utilização que tem sido feita dos laudos psicológicos e das discussões da ciência psicológica, ainda há muito o que percorrer.

Não se trata de colocar meramente um ramo do saber à disposição do outro, como outrora se dizia, também não se trata de apresentar verdades não sabidas a quem precise ouvi-las, uma vez que a Psicologia tem uma concepção de verdade que difere de outros campos. Trata-se de formalizar uma coconstrução, uma possibilidade de configurar um olhar sobre elementos comuns às duas ciências - Direito e Psicologia - que, dentre outras coisas, passa pela previsão, explicação e construção de políticas voltadas para a saúde mental. 


\section{Evani Zambon Marques da Silva}

Doutora em Psicologia Clínica pela Pontifícia Universidade Católica de São Paulo e docente da Pontifícia Universidade Católica de São Paulo, São Paulo - SP - Brasil.

E-mail: ezms@uol.com.br

Endereço para envio de correspondência:

Alameda Ministro Rocha Azevedo, 932, $2^{\circ}$ andar, ap. 21, Jardim Paulista. CEP: 01410-002. São Paulo, SP.

Recebido 17/05/2012, 1a Reformulação 20/12/2012, Aprovado 11/04/2013. 
Referências
Amaral Santos, M. (1994). Comentários ao Código de Processo Civil (7a ed.). Rio de Janeiro: Forense.

American Psychological Association. (1994). Guidelines for child custody evaluations in divorce proceedings. American Psychologist, 49(7), 677-680.

Associação dos Assistentes Sociais e Psicólogos do Tribunal de Justiça de São Paulo. (2007). Diálogos interdisciplinares: a psicologia e o serviço social nas práticas judiciárias. São Paulo: Casa do Psicólogo.

Bernardi, D. C. F. (2005). Avaliação psicológica no âmbito das instituições judiciárias. In R. M. Cruz, R. M. Maciel \& D. C. Ramirez. O trabalho do psicólogo no campo jurídico (pp.7180). São Paulo: Casa do Psicólogo.

Brasil. (1998). Código de Processo Civil e legislação processual em vigor - Lei n 5.869, de 11.01.1973.

Brasil. (1990). Estatuto da Criança e do Adolescente. Lei no 8.069, de 13.07.1990.

Camargo, A. L. C. (1982). O menor e seus direitos: audiências interprofissionais. São Paulo: Lex.

Castro, L. R. F. (2003). Disputa de guarda e visitas: no interesse dos pais ou dos filhos? São Paulo: Casa do Psicólogo.

Conselho Regional de Psicologia da 6o Região. (2010). Psicólogo judiciário nas questões de família. A ética própria da psicologia: mudanças na relação assistente técnico e perito. São Paulo: CRP SP.

Conselho Nacional de Justiça. Portal do Conselho Nacional de Justiça. Recuperado em 14 maio, 2012. Disponível em: http://www.cnj.jus.br

Conselho Federal de Psicologia. Resoluções. Recuperado em 13 maio, 2012. Disponível em http://www.pol.org.br/pol/cms/ pol/legislacao/resolucao/

Conselho Federal de Psicologia. Código de Ética Profissional do Psicólogo. Recuperado em 10 maio, 2012. Disponível em http://www.pol.org.br/pol/export/sites/default/pol/legislacao/

Fonseca, A. F., Matos, A., Simões, A. (2008). Psicologia e justiça: oportunidades e desafios. In A. C. Fonseca (Ed.). Psicologia e justiça (pp. 3-35). Coimbra, Portugal: Almedina.

Lago, V. M., Amato, P., Teixeira, P. A., Rovinski, S. L. R., \& Bandeira. D. R. (2009). Um breve histórico da psicologia jurídica no Brasil e seus campos de atuação. Estudos de Psicologia, 26 (4), 483- 491. doi: http://dx.doi.org/10.1590/ S0103-166X2009000400009

Maciel, S. K., \& Cruz, R. M. (2009). Avaliação psicológica em processos judiciais nos casos de determinação de guarda e regulamentação de visitas. In S. L. R. Rovinski \& R. M. Cruz. Psicologia jurídica: perspectivas teóricas e processos de intervenção (pp.45- 54). São Paulo: Vetor.

Marques da Silva, M. A., \& Miranda, J. (2009). Tratado lusobrasileiro da dignidade humana (2a ed.). São Paulo: Quartier Latin.

Martins, S. R. C. (1999). Perícias psicológicas judiciais e a família: proposta de uma avaliação sistêmica. (Dissertação de Mestrado). Pontifícia Universidade Católica de São Paulo, SP.

Myra y Lopes, E. (2000). Manual de psicologia jurídica. Campinas: Péritas.

Nalini, J. R. (1997). O juiz, o mundo exterior e a produção da justiça. Revista dos Tribunais, 83(705), 272-282.

Noronha, A. P. P., \& Reppold, C. T. (2010). Considerações sobre a avaliação psicológica no Brasil. Psicologia: Ciência e Profissão, 30(Esp.), 192 -201. doi: http://dx.doi.org/10.1590/S141498932010000500009

Peluso, A. C. (1997). Apresentação. In Direito de família e ciências humanas - caderno de estudos $n^{\circ} 1$ (pp.5-8). São Paulo: Jurídica Brasileira.

Pereira, R. C. (1991). O código de ética e a ética do código: algumas considerações jurídicas. Psicologia: Ciência e Profissão, 11(1-4), 32-35. Recuperado em 12 maio, 2012, de http://www.scielo.org. doi: http://dx.doi.org/10.1590/ S1414-98931991000100006

Pereira, A., \& Matos, M. (2011). Avaliação psicológica das responsabilidades parentais nos casos de separação e divórcio. In M. Matos, R. A. Gonçalves \& C. Machado (Orgs.), Manual de psicologia forense: contextos e desafios (pp. 311-347). Braga, Portugal: Psiquilibrios.

Reis, E. F. (2009). Varas de família: um encontro entre psicologia e direito. Curitiba: Juruá.

Rodriges, M. C., Couto M. C., \& Hungria M. C. L. (2005). A influência dos laudos psicológicos nas decisões judiciais das Varas de Família e Sucessões do Fórum Central da Capital de São Paulo. In S. K. Shine (Org.), Avaliação psicológica e lei: adoção, vitimização, separação conjugal, dano psíquico e outros temas (pp.19-36). São Paulo: Casa do Psicólogo.

Rovinski, S. L. R. (2004). Fundamentos da perícia psicológica. São Paulo: Vetor.

Rovinski, S. L. R. (2009). Psicologia jurídica no Brasil e na América Latina: dados históricos e suas repercussões quanto à avaliação psicológica. In S. L. R. Rovinski \& R. M. Cruz (Orgs.), Psicologia jurídica: perspectivas teóricas e processos de intervenção (pp.11-22). São Paulo: Vetor.

Rosa, M. V. F. (1999). Perícia judicial: teoria e prática. Porto Alegre: Sergio Antonio Fabris Editor.

Shine, S. K., \& Strong, M. I. (2005). O laudo pericial e a interdisciplinaridade no poder judiciário. In S. K. Shine (Org.), Avaliação psicológica e lei (pp.192-245). São Paulo: Casa do Psicólogo.

Silva, E. Z. M. (2005). Alcances e limites da psicologia jurídica: o impacto da avaliação psicológica na visão das partes envolvidas. (Tese de Doutorado). Pontifícia Universidade Católica de São Paulo, SP.

Silva, E. Z. M., \& Castro, L. R. F. (2011). Psicologia judiciária para concursos da magistratura. São Paulo: Edipro.

Silva, E. Z. M. (1999). Paternidade ativa na separação conjugal. São Paulo: Juarez de Oliveira.

Simões, M. R., \& Lopes, A. F. (2004). Contributos da avaliação para a planificação e medida da intervenção psicológica. In M. H. D. Silva, A. C. Fonseca, L. Alcoforado \& C. M. V. Vilar (Orgs.), Crianças e jovens em risco: da investigação à intervenção (pp. 165-209). Coimbra, Portugal: Almedina.

Tribunal de Justiça do Estado de São Paulo. (2008). Manual de procedimentos técnicos da atuação dos profissionais de serviço social e psicologia. Recuperado em 14 maio, 2012 de www.tjsp.jus.br.

Tribunal de Justiça do Estado de São Paulo. Normas de Serviço da Corregedoria Geral de Justiça. Recuperado em 14 maio, 2012 de www.tjsp.jus.br

Vezzulla, J. C. (2001). Teoria e prática: guia para utilizadores e profissionais. Portugal: Agora Publicações. 